\title{
To Produce, Co-produce, Enable or Co-enable? The Art of Balancing Managerial Action in Inter-Organizational Networks
}

\author{
Timo Järvensivu (Corresponding author) \\ Doctor of Science (Economics), Research Manager \\ Aalto University School of Business, B.O. Box 21210, FIN-00076 Aalto, Finland \\ Tel: 358-50-383-2483Ｅ-mail: timo.jarvensivu@aalto.fi \\ Rika Rajala \\ Master of Social Services, Aalto University School of Business \\ B.O. Box 21210, FIN-00076 Aalto, Finland \\ Tel: 358-40-545-3271 E-mail: rika.rajala@kolumbus.fi \\ Received: October 12, 2012 \\ Accepted: October 29, 2012 \\ Online Published: January 5, 2013 \\ doi:10.5430/ijba.v4n1p1 \\ URL: http://dx.doi.org/10.5430/ijba.v4n1p1
}

The research was sponsored by the European Social Fund and by the Academy of Finland.

\begin{abstract}
This paper focuses on the practice of network management. Applying the action research methodology, a study of eight elderly care development networks in two cities in Finland is presented. The results address two key managerial questions: Should the focus be on what or how? and Should network participants perform together or should some participants work on behalf of the network? These two questions are shown to relate to two of the most fundamental dimensions of any network management circumstance. Together they form a matrix of four management modes: producing (what - on behalf), co-producing (what-together), enabling (how-on behalf) and co-enabling (how - together). We argue that by carefully balancing these four management modes, a network manager can start with a weaker, more closed network and gradually build a strong, more open network.
\end{abstract}

Keywords: Action research, Health care, Network management, Inter-organizational networks

\section{Introduction}

The field of network research is as broad as it is diverse with varying backgrounds that include institutional economics, economic sociology, industrial network theory, organizational studies, political science, and strategic management (Araujo and Easton, 1996; Ebers, 1997; Grandori and Soda, 1995; Brass et al., 2004). The research encompasses various foci, ranging from the structures, functions, dynamics and outcomes of networks to their management (Jones, Hesterly and Borgatti, 1997; Möller and Svahn, 2006; Ritter, Wilkinson and Johnston, 2004; Järvensivu and Möller, 2009). We focus here on inter-organizational network management, which has been examined in several, often overlapping, fields, including industrial and business networks (Ford et al., 2003; Möller and Halinen, 1999), strategic networks (Jarillo, 1988; Möller and Rajala, 2007; Gulati, Nohria and Zaheer, 2000), innovation and development networks (Dhanaraj and Parkhe, 2006), health care networks (Provan and Milward, 1995; Provan, Isett and Milward, 2004), public policy networks (Klijn, Koppenjan and Termeer, 1995; Agranoff and McGuire, 2003; Koliba, 2011).

The body of network management research lacks comprehensiveness in the overall understanding of the actual practice of network management. Hibbert et al. (2008) have divided the insights into six categories. Three of these categories focus on conceptualizing the nature of network management challenges: life-cycle, stage, and phase models; analytical conceptualizations, typologies, models, and diagnostics; and success and failure factors. The other three categories are prescriptive, offering advice on specific managerial challenges, including competencies, behaviors, and tasks; guidelines and process steps; and tools and techniques for effective facilitation. The categorization is not precise, as it 
has overlapping and non-exhaustive categories. Still it is useful as it provides the manager with a general network management typology with "handles for reflective practice" (Hibbert et al. 2008, p. 405).

The broadness of network management research is impressive, and the categorization by Hibbert et al. (2008) is valuable in that it offers a lens to the spectrum of network management practice. Yet, we argue that the literature still leaves the manager wanting a more focused framework for day-to-day reflection on network management work. The purpose of this paper is to add clarity to the field of network management practice by asking: What are the most basic practical questions that a network manager encounters while managing an inter-organizational network? Through answering this question, we aim to construct a framework that can be regarded as one of the key 'handles' for network management practice. The importance of such a framework lay not in its broadness, but in its ability to help the manager to construct real-world and hands-on responses to the perennial question of "what should I do next?"

We acknowledge that the phenomenon of networking is inherently complex (Hibbert et al., 2008; Håkansson and Snehota, 1995; Järvensivu and Möller, 2009; Järvensivu et al., 2012). Each networking situation is quite different, starting with its more general socio-economic context and including various types of exogenous factors (e.g. history, policies, and shared practices) as well as certain endogenous factors (e.g. resources and capabilities). Despite these limitations on generalization, we, however, do posit that one can craft a model of network management practice that transcends different contexts through its situated adoption. In the next section, we offer a brief review of network management theory. Thereafter, we present our research methodology, and present the studied cases. Then we proceed to describing our empirical findings. Finally, we discuss the results and offer a few notes on both study limitations and future research.

\section{Key Facets of Network Management}

This paper focuses on management in inter-organizational contexts. Inter-organizational networks are a distinct mode of governance, apart from markets and hierarchies (Powell, 1990; Ritter, 2007; Fombrun, 1982; Brass et al., 2004; Håkansson and Ford, 2002). Network governance is characterized by long-term, reciprocal relationships between actors (individuals, teams, organizations, cliques) in which mutual expectations, collaboration, and trust are the dominant managing mechanisms (Bradach and Eccles, 1989; Powell, 1990; Adler, 2001; Håkansson and Johanson, 1992). This designation differentiates networks from markets that are guided by relatively short-term arms-length exchange relationships and negotiations, and from hierarchies characterized by fairly long-term authority based contractual relationships. In reality, these ideal modes are unlikely to exist in their purest forms. Rather, we will witness mixed modes having different degrees of hierarchy-, market-, and network-like organization (e.g., Bradach and Eccles, 1989; Powell, 1990). It is well documented that these three governance modes function best in different situations. Demand certainty or uncertainty, task complexity, human asset specificity, actor autonomy, frequency, opportunistic threat, and transactions costs in general condition the type of governance (Jones et al., 1997; Park, 1996). In simple terms, complex and knowledge-rich organizing, such as innovation activities, call for a network form of governance as opposed to hierarchical or market-based governance (Powell et al., 1996; Jones et al., 1997; Park, 1996).

It is well documented that hierarchies, markets, and networks require or favor different managerial practice (Jones, Hesterly and Borgatti, 1997; Powell, 1990). Despite the differences, however, it can be argued that there are some fundamental similarities in their management (Järvensivu and Möller, 2009; Gittell and Weiss, 2004). Analogous to the widely accepted definition of management as being planning, organizing, leading, and controlling (Tsoukas, 1994; Järvensivu and Möller, 2009), these four functions are required in any type of organized value creation in some for or the other.

Since network relationships will exist among relatively autonomous actors, network management however cannot be carried out through the application of authority. The fundamental difference is that the success of network governance rests on building trust and commitment (Hunt and Morgan, 1994b; Morgan and Hunt, 1994; Powell, 1990; Järvensivu and Möller, 2009). Their existence fosters knowledge mobility, tolerance of risk, and network stability and reduces opportunistic threat and risk, thus ultimately enabling the innovativeness of the network (Dhanaraj and Parkhe, 2006; Inkpen and Curral, 2004; Mayer et al., 1995; Park 1996). Trust helps to achieve communication, conflict management, and negotiation processes and improves satisfaction and individual as well as unit level performance (McEvily et al., 2003). Commitment is the willingness of network members to invest their time, effort, and attention in collaboration (Doz, 1996; Inkpen and Currall, 2004). Overall, trust increases the likelihood of commitment to joint activities (Håkansson and Snehota, 1995; Morgan and Hunt 1994). Both trust and commitment develop over time, as actors learn to know each other and create shared values together (Dwyer et al., 1987; Hunt and Morgan, 1994a). Highly influential and talented individuals can be of great value in strengthening trust-based social networks (Schweer et al., 2012). 
The extent to which networks can be managed is a fundamental point of disagreement among network scholars. Some argue that in closed or strategic networks with a limited number of participants, a relatively powerful hub member should be able to exert reasonably strong control among the actors (Jarillo, 1988). Others argue that individual firms have only limited control over networks that are open creatures by their very nature (Ford and Håkansson, 2006). This difference offers a continuum that ranges from relatively closed, more easily manageable "network organizations" to relatively open, largely unmanageable "networks of organizations" (Harland and Knight, 2001; Ritter et al., 2004). The two polar viewpoints can be attributed to differences in definitions and ontological views of networks. Järvensivu and Möller (2009) and Herranz (2008) however argue that it is fundamentally useless to argue that networks cannot be managed. The key issue is not whether networks can be managed, but rather what kind of governance practices are most suitable for each type of network. For instance, Hung et al. (2008) show how different network structures favor different knowledge management practices and routines.

\section{Methodology: Action Research in Elderly Care Networks}

Equipped with the theoretical understanding described above, we asked: What are the most basic practical questions that a network manager encounters while managing an inter-organizational network? A good way to approach such an open, practice oriented research question is to acquire first-hand experiential knowledge. Hence we resorted to action research (McNiff, 1995; Drummond and Themessl-Huber, 2007; White, 2004). Action research reveals the everyday practices of a studied community that cannot easily be revealed through interviews or survey research, since many people either hesitate to reveal or are unaware of underlying practices (McNiff, 1995). Action research is a process whereby the researcher gets involved in the studied community, empowers it, puts theory into practice, tries out ideas, collects a diversity of data on the dynamics and interactions taking place, reflects on key events, and in general learns from the experience to co-create new understanding along with the studied community.

Our study focused on eight development networks in the elderly care sector located in two relatively large cities in Finland, three in one city and five in the other. We chose this research setting mainly because of existing access to in-depth data, enabled by a research funding from the European Social Fund which we had received for the task of developing the elderly care networks of these two cities. More importantly, however, we knew that this setting is a rich context for network research due to its inherent variability and complexities. Namely, elderly care networks include many types of services (health care, social care, informal care), many types of experts (physicians, nurses, informal caretakers, managers), services at various hierarchical levels (primary, secondary and tertiary care), and actors from all sectors (public, private, non-profit, voluntary).

Elderly care services in Finland are increasingly under pressure, as the country's population is aging rapidly. These circumstances results in a specific direction: a clear need and ambition to develop innovations to serve the rapidly aging Finnish population while cutting down costs at the same time. In general, elderly care innovations can take many forms, including solutions targeted at formal and/or informal care; solutions that are based on markets, networks and/or hierarchies; solutions at different levels, such as institutional, intermediate, and/or the micro level; and technological and/or service related solutions (Djellal and Gallouj, 2006). The eight networks that we studied included all of these forms of innovations in some for or the other. Two networks in our study focused on improving home care services and selecting supporting technologies, and one dealt with informal care services. One of the networks conceptualized and initiated regional service and development networks for elderly services, comprised of public, private and non-profit actors. One network aimed at creating a city-level strategy for the future of elderly care services and to improve hierarchy-network relations. One of the networks targeted service delivery after an acute care episode, and another looked at new structures and services that should help the elderly stay in their homes as long as possible. One network was also developing a one-stop information service for the elderly and their relatives.

We started the action research process in spring 2008 and continued with it until spring 2011. During the research period, we participated in organizing more than 100 networking workshops. Our task was to put theoretical insights into action in these workshops through relevant managerial interventions, and then build new insights based on what we learned from the interventions. The number of participants in a single workshop ranged from about 10 to more than 100. The participants represented mostly different units of public sector elderly care organizations and units, but also NGOs, volunteers, elderly customers, and in some cases, also the private sector. The funding for the project ceased by the end of April 2011, but at least five of the seven remaining networks planned to continue their operation in one form or the other even without the external funding. One of the networks stopped its operations during the research period, when a project with similar goals was quite suddenly started at a higher level of hierarchy, ultimately consuming the stakeholders' interest to continue working with this particular network. 
The main body of our data consisted of observations from the workshops (field notes, recordings, etc.), but included also data from focus group and personal interviews, emails, phone calls, and meeting notes. The data amounted to more than 1,500 pages of text. In order to analyze such a vast amount of data, we visualized it using process diagrams (Miles and Huberman, 1994) that illustrated the development of the eight networks. We highlighted key events (workshops, meetings, etc.) in terms of their content, results, activities, and group-work methods and then identified related patterns for managerial tasks, actor roles, and levels of trust and commitment. The resulting frameworks and insights are described in the following section.

\section{Results}

The networks we studied interestingly enough portrayed varying managerial settings. As such, the context of our study, the Finnish elderly care network, is an open network on the one hand, but still hierarchically oriented on the other hand, due to Finnish health and social care legislation that places the responsibility for service organization on municipal officers. There were several exogenous factors that were influencing the networks: A more hierarchical management culture in one of the studied cities and less of one in the other; scarcity of public sector funding and a need to restructure due to a rapidly aging population and a growing need for elderly care services; and a strong aspiration to improve services and efficiency, yet an obvious lack of skills in innovation and network management practices. These factors imposed both opportunities and challenges and also certain rigidities to network management as we participated in and studied these networking processes.

The eight studied networks evolved at a differing pace and went through altering phases, such as goal-setting, trust and commitment building and fading, early innovation and innovation diffusion, growing larger and smaller, withdrawal, and even dissolution. The day-to-day problems of network management varied from such smaller issues as "how should we contact this and that person", "who pays for the coffee at the network meeting", and "when is the next possible time for a meeting that actually suits everyone" to larger matters, such as "should we invite this or that actor to our network", "how should we measure our success" and "we know what we want, but we don't know how to get there". Our findings are detailed in the next section. We use quotations to provide the reader with authenticity. The quotations were selected based on their representativeness of the complete data set, i.e., they are not merely examples, but describe key insights generalizable over the whole data set.

\subsection{Producing, Co-producing, Enabling, and Co-enabling}

We identified two fundamental patterns that seem to be pertinent for understanding all the network management situations we faced. First, we noticed that the networks struggled constantly with questions related to outcome and process: What should be done, and how can or should this be achieved? Second, the networks struggled with determining the appropriate agency for network-related activities: Should a certain activity be done by a certain actor on behalf (i.e. by someone for the network), or should the activity be co-created (i.e. done together as a network)? It seems that these two question patterns are the basis of any given network management situation.

The first question pattern, what should be done and how can or should this be achieved, is a discrete typology. It relates closely to the idea of looking at a network from two distinct perspectives: outcomes (what solutions are we to seek) and process (how or through what events and activities can we reach that outcome). A manager must analyze whether a given problem is a matter of what or how or both. Often the problem seems to be asking too many what questions and too few how questions. Endless discussion on what lets the network dwell in a world of utopias, whereas how questions help to actualize the precise tasks or outcomes that are needed. This typology of course is not a new one, but has been extensively studied and various process (or independent) and outcome (or dependent) factors have been identified. For instance, Brass et al. (2004), Araujo and Easton (1996), and Grandori and Soda (1995) have reviewed these factors. Our point is not, however, to emphasize that there are different process and outcome factors or ask which of the multitude of different factors are at play at a given situation. We accentuate the need for the network manager to identify the existence of this question pattern in the first place. Unless one identifies this dimension first, the above cited antecedent-outcome-theories will not come to play at all.

The second question pattern is a non-discrete continuum. One can perform a task completely or partially on behalf of a network, or it can be completely or partially co-performed. Both types of activities, and most likely a certain amount of iteration between them, are needed. Everything cannot be co-created, since some individuals are experts in certain areas and others are not; in other words, effectiveness in value-creation derives at least partly from an effective division of work between experts in various areas. Innovativeness, on the other hand, rests at the junctions between different areas of expertise (e.g. Powell et al. 1996). If all experts focus too narrowly on their respective areas of expertise, they can drift too far away from understanding each other. Then the capacity for innovation may deteriorate, and the long-term effectiveness of the network will weaken. Again, this finding as such is not new. The value co-creation 
literature has extensively shown the benefits and the antecedents of creating together rather than for or on behalf of others (see, for instance, Ramirez, 1999; Payne et al., 2008; Vargo and Lusch, 2008). Our point is not to merely reiterate this finding, but to emphasize the point that the network manager, in practice, has to first identify where the network stands and what kind of a production mode (co-creating or creating on behalf of others) is suitable in the given situation, and then act accordingly. Simply put, theory of co-creation will not be put to use unless one first realizes, in practice, the existence of this continuum.

Putting these two dimensions together, we found a combination of four management modes (see Figure 1). We labeled these combinations producing (working on what on behalf of the network), co-producing (working on what by working together), enabling (working on how on behalf of the network), and co-enabling (working on how by working together).

$<$ Insert Figure 1 Here $>$

Looking at the left column in Figure 1, one can outline a portrait of a manager who works on behalf of the network in matters of both what and how, for instance by producing solutions to real world problems and defining ways or how the network can implement the solutions. This type of managerial action aims to design and decide the most important issues on behalf of the network. In our case study, top managers seemed to be worried about achieving concrete results efficiently, often because of ever- increasing time and resource pressures, which made them hesitant and even reluctant to let the network to be in charge. This type of top-down managerialism led, as we saw, to the tendency of many network participants to rather passively wait for top management to handle all the important design and decision issues. This tendency was also different in the two cities we studied. One of the cities clearly had a more hierarchical culture, while the other was more horizontally oriented and had fewer layers of management. The tendency to resort to top-down managerialism was more evident in the more hierarchical city, but also was present in the more horizontal one.

In contrast, a manager operating with right-column orientation participates in both co-producing solutions and co-constructing ways of implementation. Few people in our case study were at home with this orientation in practice, although quite a few, if not all, managers did appreciate this style in principle. One or two openly opposed this orientation not only in practice but also in principle, by stating, for example, that "it is ultimately the job of the top management to design the goals and means of the organization, and I [as a top manager] am happy to support you [the network] and give time for you to come up with good solutions, but if you do not come up with them fairly soon, I will then make the necessary decisions". Evidently, this kind of a response indicates opposition to co-creative networking, since it demonstrates distrust towards the network's capability and its commitment to produce solutions or find ways to progress.

Regarding the creation-co-creation dimension, we quickly realized that both those working on behalf of the network and those helping the network to co-create are needed, but in different situations. The organizational culture is one important deciding factor for the choice of the appropriate management style. Our study involved two cities, one of which has a more hierarchical management culture, and the other, a more horizontal one. In the more hierarchical setting, management was required to first produce the "what's" and "how's" of the network. Since these network participants were more used to implementing than deciding, their legitimate way of operating was to first listen to the managers and only then operate. Our network-oriented co-creative style did not initially mix well with these network participants' hierarchical backbone. They openly asked us to "please, tell us what we should do next", and when we complied, they gave positive feedback that "your design helped us to move forward with the concrete stuff, thank you". While on the upside, we managed to help the network go forward, the downside was that we helped the network to remain passive producers rather than learn to engage in active co-creation. In the other hand, the more horizontal city people were more apt to jump straight into a designing and deciding mode. However, they too lacked the necessary skills to fully engage in co-innovation.

In the beginning, a network may lack proper institutions, infrastructure, or frameworks for effective co-production and co-creation, thus requiring production and enabling activities. For instance, someone will need to gather the network and organize meetings frequently enough, so that ideas can first start flowing and then keep the motion going and fresh: "Especially in the beginning of collaboration, there should not be too long pauses between meetings, or otherwise the point gets lost, like "where were we again?"' The network also needs tools and facilitation that enable co-creative dialogue. For instance, it may be a good idea to have "workshops" and try out new groupwork and dialogue methods instead of the old habit of simply "having meetings". These techniques can help people free themselves from their habitual means of operating, as we noted in a study diary: "This 'learning cafe' method seemed to work. The people were discussing lively, and [the top managers that were present] also seemed to like the method and its results. The 
method brought with it lively discussions and new ideas. It also empowered the people to really discuss instead of working under pressure from outside control or guidance."

Out of the four management modes, co-enabling was least used. As network researchers and facilitators, we perhaps best represented this orientation, so during the project we developed the habit to always ask for how instead of what, and to push for co-creation instead of letting anyone work alone. Perhaps this was easier for us because we were not responsible for (short run) efficiency. When doing this, we sometimes were faced with evident resistance. The participants did not want to "waste our time on chitchatting", but wanted to have a "well organized process, and timely information", so that they could focus on "developing the concrete stuff". These situations seemed to require the top managers to design, jumpstart, and facilitate the network on the how issues. However, we also witnessed a downside in the top management resorting to decide on the how, since the what-issues often did not translate into commitment to the how-activities designed by the top management. The best result we sensed seems to arise from a constant iteration or a positive cycle between what and how, while at the same time trying to champion co-creation instead of working for or on behalf of the network.

Once a network is strong enough, i.e., it contains an atmosphere of trust and a critical mass of committed participants, and knowledge flows well between co-creating actors, our study supported the conclusion that letting the network find its own way - to co-enable rather than enable - helped increase the longevity of the network and the commitment of the network participants. This focus, however, may be the most difficult of the four modes of management to implement. Especially if the organizational cultures of the network participants support or are locked into a hierarchical mode, that network is likely to lack the necessary skills and motivation for attaining self-enabling networking. We found it helpful to improve these skills by educating the participants in terms of network management theory and then helping them put the theory into practice. In a feedback interview, the participants valued this educative effort: "(Respondent 1) I have found it very interesting, that [the researcher] has held these lessons of networking theory. I have learned a lot, and these lessons have raised my faith in that this [networking] is a beneficial thing, although my faith has been tested once and again. But really this has not been a time wasted. (R2) We could have had more of these [learning sessions]. (R3) Without theory this would have been futile. (RI) I agree. [This researcher] has been an outstanding workshop facilitator. For instance, if I was feeling down in the morning, it did not take long before [the researcher] got me going. (R2) Yes, [the researcher] truly made us think and did not give anything readymade. Everyone has been heard, and [the researcher] got even the silent ones to say something."

$<$ Insert Table 1 Here>

As the above discussion shows, individually, each of the resulting four managerial orientations - producing, co-producing, enabling, and co-enabling - has both strengths and weaknesses (see Table I). As such, they are not $a$ priori either superior or inferior compared to each other. Instead, they fit for better or worse into different networking situations, and each network evolves and grows stronger as it iteratively balances the different modes as time passes. Theoretically, these modes represent 'meta-roles' or 'meta-functions' in relation to the roles identified by Snow et al. (1992), Knight and Harland (2005) and Heikkinen et al. (2007) and the functions described by Järvensivu and Möller (2009). For instance, the roles of an architect and a caretaker and the functions of planning/framing and leading/mobilizing can take on very different manifestations depending whether they are performed by a manager for the network or if the network participants engage in these roles and functions together.

\subsection{Balancing the Four Modes of Management to Build an Open Network}

Interestingly, we found that the two-by-two matrix presented in Figure 1 seems to rest on a more fundamental diagonal continuum from closed to open networks or from planned to emerging networks, a continuum frequently cited in the network literature (e.g., Järvensivu and Möller, 2009; Tikkanen and Parvinen, 2006). We argue that the acts of producing tend to close the network because actors are usually less willing to commit to products they have not been part of producing. Acts of co-producing, on the other hand, are useful in opening a network. Enabling the network may also work toward opening or closing the network, but only the acts of co-enabling - equal and open opportunity for all to decide the goals and means of the network - are the epitomes of a culture of open networking.

Theoretically, an open network is not needed in all kinds of situations (Järvensivu and Möller, 2009; Möller et al., 2005). A closed network that operates in a more hierarchical manner may sometimes be more efficient in providing consistent high-quality production (Möller et al., 2005). Nevertheless it has been quite well established that a more open network is required to build long-term success in terms of innovations (Powell et al., 1996; Dhanaraj and Parkhe, 2006). While it would be, from an innovation viewpoint, desirable to set up an open network, actualizing one may not always be feasible, at least not in the short term. There are at least three caveats. First, an open network is constantly in emergence, which requires that there is momentum and commitment to co-enable both its existence and evolution. 
Should its existence rest on the commitment of just one or a few actors alone, it would be more or less closed. Second, open networks require at least some institutionalized structures that support its basic existence (e.g. a common language as well as proper communication channels), which do take time to form. Their formation may be initiated or hastened by individual actors, but enablement by individual actors tends to be unidirectional (creative), and again requires a broader effort of commitment building to make it be bidirectional (co-creative). Third, each actor in a network has its own goals and desires, which may work for or against the creation of an open network. There is a need for a critical mass of those that see that there is a win-win game there instead of perhaps only win-lose.

For an individual manager, the continuum that runs from open to closed networking is linked to the manager's continuum of control over the other actors. The more closed the network, the more the manager has control over the others. At the open end of the continuum, as each individual is free to participate or not participate, an individual manager is relatively powerless - but gains something else, i.e. the opportunity to participate in the co-production of innovations. Sometimes it is necessary to operate with a more closed network to accomplish results in an efficient manner. Sometimes there is a need to open the network and allow the distribution of control in order to extend the network's long-term effectiveness.

The problem often is that managers, bounded by limited resources, seem to favor control over productivity via closed networking rather the promise of innovation via open networking, as, for example, we noted in one important planning meeting: "I [a researcher] kept trying to emphasize that we should plan how we enable the network to discuss these issues together, and not put our effort into dealing with issues related to the network's substance. This [enabling the network] is what this project is about! But [the manager] kept on emphasizing that 'we need to set limits to what is discussed in the workshops.' I tried to remind that this is against open networking, but this idea just did not seem to go forward at all. --- There was a clear divide between [the manager's] and our project's thinking. From the viewpoint of our project work shopping should be A) participatory and B) open in a way that the active worker is the network together, not something to be done by the planning team. --- But from [the manager's] viewpoint work shopping should be A) participatory but B) closed in a way that the possible choices to be made are predetermined in order to 'focus' and discuss about the 'correct' issues."

In order for this network to open up to the possibility of open solutions, managers need to learn to devote resources to open co-creation. Opening up the network does not mean that everything must be open. This is a matter of balancing. But it does seem that having too few closed discussions is rarely the problem in a network; rather the problem is having too few open discussions. Building an open network thus seems to be much more difficult than building and maintaining a closed one. Even though radical innovation in elderly care is needed in Finland as the country is aging rapidly, this sector seems to be locked into hierarchical organizing that prevents effective innovation, and moving toward more innovative open networking is painfully slow. A more open network would be needed to open up the field for innovativeness. One manager, who wanted to build an open network, but having worked in a hierarchical culture for a long time, exemplified this point well when we started one of our network workshops: "I want you to open up for new ideas and new connections - but if you are not able to come up with a solution quickly enough, I will make the decision by myself." This manager had good intentions to open his/her network, but it is fairly evident which of the attitudes in this short sentence - "to open up for new ideas" or "I will decide by myself" - won at the workshop. As one of the participants later explained: "Our culture is that the managers always design and decide, so why would we bother trying ourselves."

Managers need to balance their efforts carefully when building an open network. Jumping from a closed network to an open one does not happen overnight. If a network begins with a strongly closed culture, it may be counterproductive for a manager to raise his or her hand and say (which is what we witnessed many times in our study): "Until now I have made too many decisions and kept things to myself. Now we have a network, so I will listen to you now and let you work. Go ahead, I'll wait for you." Result - silence. Silence will prevail, since the group has been used to waiting for others to make the first move, so they are now paralyzed in the face of such sudden openness. For instance, if a network is assigned a broad overall goal, or it has many issues on its agenda, its members may feel that someone from the outside should choose a narrower focus for them. This sentiment was expressed quite often in our study: "The focus has been a bit lost every time. There have been a huge number of themes to cover. Everyone is playing a different tune. Like we would have gathered a symphony orchestra and different musicians together without an orchestra leader who would draw everyone together to say, 'Let's play this.' This kind of network will never get anything accomplished. There has to be that someone who will take control of the process, an orchestra leader to hold it together." The participants did not realize that it was up to them to find the precise focus by working together. Since sudden openness rarely seems to work, managers should learn to build openness slowly and gradually build co-production and co-enabling opportunities over time. 
Finally, commitment fosters further commitment, while a falling rate of involvement in networking sessions and workshops erodes current and future commitment: "A good experience of networking is one where there are a lot of participants and everyone are enthusiastic and participate in the discussion. There's a feeling that the group is really doing something that is of joint interest. This is good in an enthusiastic group, that it gives value to your efforts. On the contrary there are these experience, where people are tired of the work, and it can be that a lot of people are missing, and then those that are there get frustrated that, hey, why on earth are we waiting for them. I have experienced both sentiments in a single network in different workshops, so that this changes a lot." A manager should remain sensitive to the level of commitment and whether production, co-production, enabling, or co-enabling best suits his situation and that of his network in a given situation to build trust and commitment.

\section{Conclusions}

Network management is a multifaceted concept in terms of both conceptualization and practical use, and it has been studied from numerous perspectives and in various contexts. We sought better understanding of what it is at its practical core. Acknowledging the vast range of possible theories to consider, and recognizing that all networks in their complexities are ultimately more or less idiosyncratic, we wanted to provide an empirically grounded model of the fundamentals of network management practice. In order to accomplish this goal, we utilized the action research method and examined the management of specific networks in a specific context, elderly healthcare development in Finland. We were involved as both researchers and active participants in network management in eight development networks in two cities in Finland, and held over 100 workshops for these networks over about three years. We collected and analyzed more than 1.500 pages of empirical data.

We learned that there are two key questions that network managers should be sensitive to in their efforts. Should the network focus on what or how and, second, regarding the tasks that the network is faced with, should the network perform together or should it let someone work on behalf of the network? These two questions, we argue, define two of the most fundamental dimensions of network management practice: what - how and on behalf- together. These two dimensions in turn formed a matrix of four management modes: Producing (what - on behalf), co-producing (what - together), enabling (how - on behalf) and co-enabling (how - together). We argue that by carefully moving or iterating from producing to co-producing and from enabling to co-enabling, a network manager can start with a more closed or hierarchically oriented network and build a more open or horizontally oriented, innovation-capable network. It is a gradual process of building trust and commitment to the joint undertaking, with both ups and downs while going down the road. While a more closed network may be required in some situations, building an open network is often beneficial because it provides a foundation for longer-lasting innovativeness.

We argue throughout this paper that a network manager's success at good networking depends on his or her skills to balance the four modes of network management and apply them in situ. Network management thus is not merely about finding an optimal state, but rather excelling at the process of balancing and combining the four modes of management so as to foster trust and commitment in the network, as the network engages in joint activities to have better ability to set and attain goals. In line with Provan et al. (2004b), Imperial (2005), and Page (2003), we find that the legitimacy for a network grows over time through sustained commitment and, since failures easily decrease the level of trust and commitment, managers should avoid situations with a high risk of failure by opening the network too quickly. This process may involve opening up the network, but it may also involve closing the network or parts of it, if required. The network manager will need to ask whether each situation requires actions or decisions on behalf of the network or instead participation in the performance and decision-making processes of that network as they emerge. Over time, a constant search for the best balance of these qualities will make the network stronger.

Our empirical findings are delimited by their analyzed context. However, we believe that the framework is not uniquely applicable to this one context alone. Even the Internet, perhaps the most non-hierarchical network of all, was built through a balancing act of four network management modes. Arpanet, the Internet's starting point, was enabled by the US Department of Defense. The first actors to actually produce content were its users (researchers from universities and the military). Gradually, forms of co-production, such as Bulletin Boards and IRC (Internet Relay Chat; Bulletin Boards and the IRC are forms of electronic peer-to-peer communication media) discussions emerged, enabled by the people and organizations who were building and expanding the network. Over time the Internet as a network started to operate as a fairly unlimited space of co-operation where individual co-operative activities fueled ever more co-operation through simultaneous acts of enabling, production and co-production. The advent of 'Internet 2.0', or cloud-based peer-to-peer computing and services, enabled a co-enabling mode of operation, where service providers in the cloud together constantly created new ways of operating within the Internet. Recent trends in the development of the Internet show that balancing does not need always to foster openness, as social media like 
Facebook exemplifies. Facebook has built a rather closed form of networking, so as to provide better opportunities for social co-production, along with the 'cost' of closing opportunities for co-enabling.

Further research on the resulting framework should be conducted to extend it in a broader range of contexts and theories. Perhaps most crucially, we need to examine how managers will in fact adopt and perceive the usability of this framework - does it work or not, is it helpful or not, and can they take in into daily use or not?

\section{References}

Adler, P. S. (2001). Market, Hierarchy, and Trust: The Knowledge Economy and the Future of Capitalism. Organization Science, 12(2), 215-34. http://dx.doi.org/10.1287/orsc.12.2.215.10117

Agranoff, R., \& McGuire, M. (2003). Collaborative Public Management: New Strategies for Local Governments. Georgetown University Press, Washington, D.C.

Araujo, L., \& Easton, G. (1996). Networks in Socioeconomic Systems: A Critical Review. In Iacobucci, D., (Ed.), Networks and Marketing (pp. 63-107). Thousand Oaks: Sage Publications.

Bradach, J.L., \& Eccles, R.G. (1989). Price, authority, and trust: from ideal types to plural forms. Annual Review in Sociology, 15, 97-118. http://dx.doi.org/10.1146/annurev.so.15.080189.000525

Brass, D. J., Galaskiewicz, J., Greve, H. R., \& Tsai, W. (2004). Taking stock of networks and organizations: A multilevel perspective. Academy of Management Journal, 47, 795-817. http://dx.doi.org/10.2307/20159624

Dhanaraj, C., \& Parkhe, A. (2006). Orchestrating innovation networks. Academy of Management Review, 31(3), 659-669. http://dx.doi.org/10.5465/AMR.2006.21318923

Djellal, F., \& Gallouj, F. (2006). Innovation in Care Services for the Elderly. The Service Industries Journal, 26(3), 303-327. http://dx.doi.org/10.1080/02642060600570943

Doz, Y. (1996). The Evolution of Cooperation in Strategic Alliances: Initial Conditions or Learning Processes? Strategic Management Journal, 17(1), 55-83. http://dx.doi.org/10.1002/smj.4250171006

Drummond, J., \& Themessl-Huber, M. (2007). The Cyclical Process of Action Research: The contribution of Gilles Deleuze. Action Research, 5(4), 339-357. http://dx.doi.org/10.1177/1476750307077317

Dwyer, R.F., Schurr, P.H., \& Oh, S. (1987). Developing Buyer-seller Relationships. Journal of Marketing, 51(2), 11-27. http://dx.doi.org/10.2307/1251126

Ebers, M. (1997). Explaining Inter-organizational network formation. In M. Ebers (Ed.), The Formation of inter-organizational networks (pp. 3-40). Oxford: Oxford University Press.

Fombrun, C. J. (1982). Strategies for Network Research in Organizations. Academy of Management Review, 7, $280-91$.

Ford, D., Gadde, L.-E., Håkansson, H., \& Snehota, I. (2003). Managing business relationships. Chichester: John Wiley and Sons.

Ford, David, \& Håkansson, Håkan. (2006). IMP - Some things achieved: Much more to do. European Journal of Marketing, 40(3/4), 248-258. http://dx.doi.org/10.1108/03090560610648039

Gittell, J., \& Weiss, L. (2004). Coordination Networks Within and Across Organizations: A Multi-level Framework. Journal of Management Studies, 41(1), 127-153. http://dx.doi.org/10.1111/j.1467-6486.2004.00424.x

Grandori, A., \& Soda, G. (1995). Inter-firm Networks: Antecedents, Mechanisms and Forms. Organization Studies, 16(2), 183-214. http://dx.doi.org/10.1177/017084069501600201

Gulati, R., Nohria, N., \& Zaheer, A. (2000). Strategic Networks. Strategic Management Journal, 21(3), 203-215. http://dx.doi.org/10.1002/(SICI)1097-0266(200003)21:3<203::AID-SMJ102>3.0.CO;2-K

Håkansson, H., \& Johanson, J. (1992). A Model of Industrial Networks. In B. Axelsson and G. Easton (Eds.), Industrial Networks: A New View of Reality (pp. 28-34). London: Routledge.

Håkansson, H., \& Ford, D. (2002). How Should Companies Interact in Business Environments. Journal of Business Research, 55(2), 133-139. http://dx.doi.org/10.1016/S0148-2963(00)00148-X

Håkansson, H., \& Snehota, I. (Eds.) (1995). Developing Relationships in Business Networks. London: Routledge.

Harland, C. M., \& Knight, L. A. (2001). Supply Network Strategy: Role and Competence Requirements. International Journal of Operations and Production Management, 21(4), 476-489. http://dx.doi.org/10.1108/01443570110381381 
Heikkinen, M., Mainela, T., Still, J., \& Tähtinen, J. (2007). Roles for managing in mobile service development nets. Industrial Marketing Management, 36(7), 909-925. http://dx.doi.org/10.1016/j.indmarman.2007.05.014

Herranz, J. Jr. (2008). The Multisectoral Trilemma of Network Management. Journal of Public Administration Research and Theory, 18(1), 1-31. http://dx.doi.org/10.1093/jopart/mum004

Hibbert, P., Huxham, C., \& Ring, P.S. (2008). Managing Inter-organizational Relations. In S. Cropper, M. Ebers, M., C. Huxham \& P.S. Ring (Eds.), The Handbook of Inter-organizational Relations (pp. 391-416). Oxford: Oxford University Press.

Hung, H-M., Wu, S-H., Wen, C-T., \& Wu, F-S. (2008). Competitive advantages of managing an effective social network structure to stimulate innovation from a knowledge management perspective. International Journal of Technology Management, 43(4), 363-382. http://dx.doi.org/10.1504/IJTM.2008.020556

Hunt, S.D., \& Morgan, R., M. (1994a). Organizational Commitment: One of Many Commitments or Key Mediating Construct? The Academy of Management Journal, 37(6), 1568-1587. http://dx.doi.org/10.2307/256799

Hunt, S.D., \& Morgan, R.M. (1994b). Relationship Marketing in the Era of Network Competition. Marketing Management, 3(1), 18-28.

Imperial, M. T. (2005). Using Collaboration as a Governance Strategy: Lessons From Six Watershed Management Programs. Administration \& Society, 37(3), 281-320. http://dx.doi.org/10.1177/0095399705276111

Inkpen, A.C., \& Currall, S.C. (2004). The Coevolution of Trust, Control, and Learning in Joint Ventures. Organization Science, 15(5), 586-599. http://dx.doi.org/10.1287/orsc.1040.0079

Jarillo, J. C. (1988). On Strategic Networks. Strategic Management Journal, 9(1), 31-41. http://dx.doi.org/10.1002/smj.4250090104

Järvensivu, T., \& Möller, K. (2009). Metatheory of Network Management: A Contingency Approach. Industrial Marketing Management, 38(6), 654-661. http://dx.doi.org/10.1016/j.indmarman.2009.04.005

Järvensivu, T., Nykänen, K., \& Rajala, R. (2012). A Holistic Model of Innovation Network Management: Action Research in Elderly Health Care. In H. Melkas and V. Harmaakorpi (Eds.), Practice-Based Innovation: Insights, Applications and Policy Implications (pp. 369-392). Berlin: Springer. http://dx.doi.org/10.1007/978-3-642-21723-4_19

Jones, C., Hesterly, W. S., \& Borgatti, S. P. (1997). A General Theory of Network Governance: Exchange Conditions and Social Mechanism. Academy of Management Review, 22(4), 911-945.

Klijn, E., Koppenjan, J., \& Termeer, K. (1995). Managing Networks in the Public Sector: A Theoretical Study of Management Strategies in Policy Networks. Public Administration, 73(3), 427-454. http://dx.doi.org/10.1111/j.1467-9299.1995.tb00837.x

Knight, L., \& Harland, C. (2005). Managing supply networks: Organizational roles in network management. European Management Journal, 23(3), 281-292. http://dx.doi.org/10.1016/j.emj.2005.04.006

Koliba, C. (2011). Performance Management in Governance Networks-Critical Concepts and Practices. Public Performance \& Management Review, 34(4), 515-519. http://dx.doi.org/10.2753/PMR1530-9576340404

Mayer, R., Davis, J., \& Schoorman, D. (1995). An Integrative Model of Organizational Trust. Academy of Management Review, 20(3), 709-734.

McEvily, B., Perrone, V., \& Zaheer, A. (2003). Trust as an Organizational Principle. Organizational Science, 14(1), 91-103. http://dx.doi.org/10.1287/orsc.14.1.91.12814

McNiff, J. (1995). Action Research: Principles and Practice. London: Routledge.

Miles, M. B., \& Huberman, A. M. (1994). Qualitative Data Analysis: An Expanded Sourcebook (2nd ed.). SAGE Publications, Thousand Oaks.

Möller, K., \& Rajala, A. (2007). Rise of strategic nets - New modes of value creation. Industrial Marketing Management, 36(7), 895-908. http://dx.doi.org/10.1016/j.indmarman.2007.05.016

Möller, K. K., \& Halinen, A. (1999). Business Relationships and Networks: Managerial Challenge of Network Era. Industrial Marketing Management, 28(5), 413-427. http://dx.doi.org/10.1016/S0019-8501(99)00086-3

Möller, K., \& Svahn, S. (2006). Role of Knowledge in Value Creation in Business Nets. Journal of Management Studies, 43, 985-1007. http://dx.doi.org/10.1111/j.1467-6486.2006.00626.x 
Möller, K., Rajala, A., \& Svahn, S. (2005). Strategic Business Nets - Their Type and Management. Journal of Business Research, 58(9), 1274-1284. http://dx.doi.org/10.1016/j.jbusres.2003.05.002

Morgan, R. M., \& Hunt, S. D. (1994). The Commitment-Trust Theory of Relationship Marketing. Journal of Marketing, 58(3), 20-38. http://dx.doi.org/10.2307/1252308

Page, S. (2003). "Virtual" Health Care Organizations and the Challenges of Improving Quality. Health Care Management Review, 28(1), 79-92. http://dx.doi.org/10.1097/00004010-200301000-00009

Park, S. H. (1996). Managing an Interorganizational Network: A Framework of the Institutional Mechanism for Network Control. Organization Studies, 17(5), 795-824. http://dx.doi.org/10.1177/017084069601700505

Payne, A. F., Storbacka, K., \& Frow, P. (2008). Managing the Co-creation of Value. Journal of the Academy of Marketing Science, 36(1), 83-96. http://dx.doi.org/10.1007/s11747-007-0070-0

Powell, W. W. (1990). Neither market nor hierarchy: Network forms of organization. Research in Organizational Behavior, 12, 295-336.

Powell, W. W., Koput, K. W., \& Smith-Doerr. L. (1996). Interorganizational Collaboration and the Locus of Innovation: Networks of Learning in Biotechnology. Administrative Science Quarterly, 41, 116-145. http://dx.doi.org/10.2307/2393988

Provan, K. G., \& Milward, H. B. (1995). A preliminary theory of interorganizational network effectiveness: A comparative study of four community mental health systems. Administrative Science Quarterly, 40(1), 1-33. http://dx.doi.org/10.2307/2393698

Provan, K. G., Isett, K. R., \& Milward, H. B. (2004). Cooperation and compromise: A network response to conflicting institutional pressures in community mental health. Nonprofit and Voluntary Sector Quarterly, 33, 489-514. http://dx.doi.org/10.1177/0899764004265718

Provan, K. G., Lamb, G., \& Doyle, Mary. (2004b). Building Legitimacy and the Early Growth of Health Networks for the Uninsured. Health Care Management Review, 29(2), 117-128. http://dx.doi.org/10.1097/00004010-200404000-00005

Ramirez, R. (1999). Value Co-production: Intellectual Origins and Implications for Practice and Research. Strategic Management Journal, $20,49-65$. http://dx.doi.org/10.1002/(SICI)1097-0266(199901)20:1<49::AID-SMJ20>3.0.CO;2-2

Ritter, T. (2007). A Framework for Analyzing Relationship Governance. Journal of Business and Industrial Marketing, 22(3), 196-201. http://dx.doi.org/10.1108/08858620710741904

Ritter, T., Wilkinson, I. F., \& Johnston, W. J. (2004). Managing in Complex Business Networks. Industrial Marketing Management, 33(3), 175-183. http://dx.doi.org/10.1016/j.indmarman.2003.10.016

Schweer, M., Assimakopoulos, D., Cross, R., \& Robert, J. T. (2012). Building a well-networked organization. MIT Sloan Management Review, 53(2), 35-42.

Snow, C. C., Miles, R. E., \& Coleman, H. J., Jr. (1992). Managing 21st Century Network Organizations. Organizational Dynamics, 20(3), 5-20. http://dx.doi.org/10.1016/0090-2616(92)90021-E

Tikkanen, H., \& Parvinen, P. (2006). Planned and spontaneous orders in the emerging network society. Journal of Business \& Industrial Marketing, 21(1), 38-49. http://dx.doi.org/10.1108/08858620610643166

Tsoukas, H. (1994). What is management? An outline of a metatheory. British Journal of Management, 5, 289-301. http://dx.doi.org/10.1111/j.1467-8551.1994.tb00080.x

Vargo, S. L., \& Lusch, R. F. (2008). Service-Dominant Logic: Continuing the Evolution. Journal of the Academy of Marketing Science, 36(1), 1-10. http://dx.doi.org/10.1007/s11747-007-0069-6

White, A. (2004). Lewin's Action Research Model as a Tool for Theory Building: A Case Study from South Africa. Action Research, 2(2), 127-144. http://dx.doi.org/10.1177/1476750304043727 
Table 1. The strengths and weaknesses of the four managerial modes

\begin{tabular}{|c|c|c|}
\hline \multirow{2}{*}{$\begin{array}{l}\text { Management Mode } \\
\text { Working with network } \\
\text { production (producing } \\
\text { or co-producing) }\end{array}$} & Strengths (+) & Weaknesses (-) \\
\hline & $\begin{array}{l}\text { - In the end, only the resulting production } \\
\text { makes investments into a network } \\
\text { worthwhile and legitimate }\end{array}$ & $\begin{array}{l}\text { - Too much focus on production and too little } \\
\text { focus on network evolution will be } \\
\text { detrimental to long-term network success }\end{array}$ \\
\hline \begin{tabular}{l|l} 
& Producing
\end{tabular} & $\begin{array}{l}\text { - Production rate may be quick, which in } \\
\text { and of itself may improve the commitment } \\
\text { to the overall networking process }\end{array}$ & $\begin{array}{l}\text { - Others beside the producer may become } \\
\text { alienated and less committed to adopt the } \\
\text { products } \\
\text { - Products are the result of a limited } \\
\text { knowledge base }\end{array}$ \\
\hline Co-producing & $\begin{array}{l}\text { - Products are the results of a broader } \\
\text { knowledge base } \\
\text { - Those involved in co-production are more } \\
\text { likely committed to adopting the products }\end{array}$ & $\begin{array}{l}\text { - Production rate may be slow and unstable, } \\
\text { which may alienate those that expect a } \\
\text { quicker and more reliable production rate }\end{array}$ \\
\hline $\begin{array}{l}\text { Working with network } \\
\text { evolution (enabling or } \\
\text { co-enabling) }\end{array}$ & $\begin{array}{l}\text { - A well-functioning network is more likely } \\
\text { to produce innovations than is a } \\
\text { dysfunctional network }\end{array}$ & $\begin{array}{l}\text { - Too much focus on network evolution and } \\
\text { too little focus on production alienates } \\
\text { outcome-oriented network members }\end{array}$ \\
\hline \begin{tabular}{l|l} 
Enabling \\
\end{tabular} & $\begin{array}{l}\text { - Evolution may be quick, which may help } \\
\text { the network to start producing more quickly } \\
\text { - Evolution is likely more predictable and } \\
\text { stable, which is required in many } \\
\text { managerial situations }\end{array}$ & $\begin{array}{l}\text { - Others beside the enabler may become } \\
\text { alienated and thus less committed to the } \\
\text { networking process } \\
\text { - Evolution is based on a limited knowledge } \\
\text { base, resulting in sub-optimal evolution and } \\
\text { lower innovation potential }\end{array}$ \\
\hline Co-enabling & $\begin{array}{l}\text { - Evolution is the result of a broader } \\
\text { knowledge base, resulting in greater } \\
\text { innovation potential } \\
\text { - Those involved in co-enabling are more } \\
\text { committed to the networking process } \\
\text { - Evolution is more chaotic, and unexpected } \\
\text { turns may have good effects, resulting in } \\
\text { greater innovation potential }\end{array}$ & $\begin{array}{l}\text { - Evolution may be slow, which may alienate } \\
\text { those who expect quicker development } \\
\text { - Evolution is more chaotic, and unexpected } \\
\text { turns may have ill effects }\end{array}$ \\
\hline
\end{tabular}

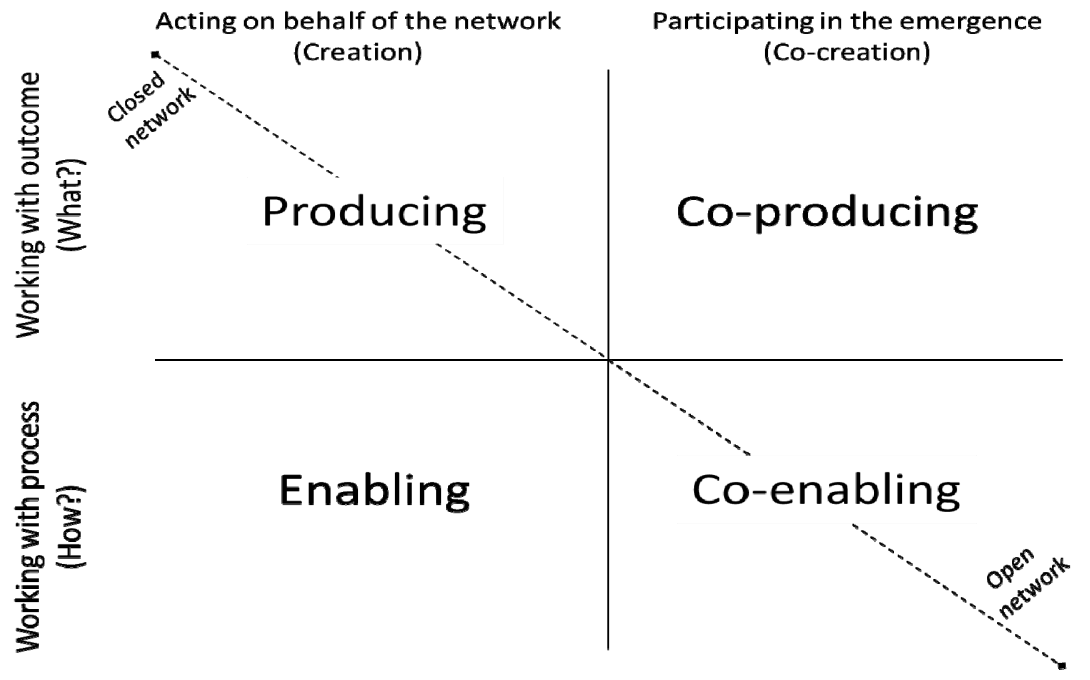

Figure 1. The four modes of network management 